\title{
Problem-based learning and case-based learning in dental education
}

\author{
Haiyan Wang ${ }^{1 \#}$, Jing Xuan ${ }^{2 \#}$, Lijun Liu ${ }^{1}$, Xuemin Shen ${ }^{1 *}$, Yaoyang Xiong ${ }^{3 *}$ \\ ${ }^{1}$ Department of Oral Mucosa, Shanghai Ninth People's Hospital, College of Stomatology, Shanghai Jiao Tong University School of Medicine, \\ National Clinical Research Center For Oral Diseases, Shanghai Key Laboratory of Stomatology \& Shanghai Research Institute of Stomatology, \\ Shanghai, China; ${ }^{2}$ Oral Department, Shanghai Municipal Hospital of TCM Affiliated to Shanghai TCM University, Shanghai, China; ${ }^{3}$ Department \\ of Prosthodontics, Shanghai Ninth People's Hospital, College of Stomatology, Shanghai Jiao Tong University School of Medicine, National Clinical \\ Research Center For Oral Diseases, Shanghai Key Laboratory of Stomatology \& Shanghai Research Institute of Stomatology, Shanghai, China \\ Contributions: (I) Conception and design: H Wang, Y Xiong; (II) Administrative support: X Shen; (III) Provision of study materials or patients: \\ J Xuan, L Liu, H Wang; (IV) Collection and assembly of data: Y Xiong, H Wang; (V) Data analysis and interpretation: Y Xiong, H Wang; (VI) \\ Manuscript writing: All authors; (VII) Final approval of manuscript: All authors. \\ "These authors contributed equally to this work. \\ *These authors contributed equally to this work. \\ Correspondence to: Yaoyang Xiong. Department of Prosthodontics, Shanghai Ninth People's Hospital, College of Stomatology, Shanghai Jiao Tong \\ University School of Medicine, National Clinical Research Center For Oral Diseases, Shanghai Key Laboratory of Stomatology \& Shanghai \\ Research Institute of Stomatology, Shanghai, China. Email: yaoyang_x@163.com; Xuemin Shen. Department of Oral Mucosa, Shanghai Ninth \\ People's Hospital, College of Stomatology, Shanghai Jiao Tong University School of Medicine, National Clinical Research Center For Oral Diseases, \\ Shanghai Key Laboratory of Stomatology \& Shanghai Research Institute of Stomatology, Shanghai, China. Email: kiyoshen@163.com.
}

Background: Numerous novel teaching methods have been developed in recent times for use in medical education. Of these methods, problem-based learning (PBL) and case-based learning (CBL) have attracted the most attention. We evaluated and compared the efficiency of these two teaching methods in dental education and discussed the importance of teachers to these courses. This study aims to evaluate the efficiency of PBL and CBL in dental education, and discuss the importance of teachers to the courses.

Methods: In this study, 28 students enrolled in a seven-year program at the College of Stomatology at Shanghai Jiao Tong University were chosen as participants. In the fourth year, PBL combined with independent learning was used to teach students the theory of oral mucosal diseases. During the internship, CBL was used to present specific cases. Both methods were carried out with group discussion. After the PBL course, teachers assessed its effect by the students' class performance, their ability to collect data, and group cooperation. After the CBL course, its effect was assessed by the students' ability in history-taking, diagnosis and antidiastole, and case analysis. In addition, the teachers' roles in both methods were assessed by both the students and the teachers themselves. Data was collected by questionnaire survey and statistically analyzed with SPSS Statistics 20.

Results: PBL significantly improved students' self-learning abilities in the theory course. CBL helped students make diagnoses and develop treatment plans for actual cases in the internship. Both students and teachers thought that teachers were indispensable to both PBL and CBL. There was no difference between student and teacher views.

Conclusions: Although PBL and CBL have different focuses, their combination may enhance teaching effectiveness in dental education. Additionally, teachers play an important role in the application of both these teaching methods.

Keywords: Problem-based learning (PBL); case-based learning (CBL); dental education; oral mucosal disease; teaching methods 
Submitted Jun 15, 2020. Accepted for publication Feb 18, 2021.

doi: $10.21037 / \mathrm{atm}-21-165$

View this article at: http://dx.doi.org/10.21037/atm-21-165

\section{Introduction}

Oral mucosal disease comes in several types, all which have complex causes and exhibit diverse clinical manifestations. This disease is closely related to psychosocial factors and the general physical condition of a patient. Additionally, oral mucosal disease is known to have an unclear etiology and to be difficult to diagnose and treat. Oral mucosal disease as a subject of dental education includes immunology, microbiology, pathology, pharmacology, dermatology, as well as other disciplines. Traditional teaching methods involve primarily conveying knowledge, with teachers being the subjects. However, the salient features of oral mucosal disease are numerous and complicated. Due to this, traditional teaching cannot effectively summarize this subject, which causes course content to become cluttered. Student participation is low when traditional teaching methods are used, and they are easily distracted during the teaching process. Additionally, traditional teaching methods do not allow students to provide effective and timely feedback on their acquired knowledge. Novel teaching methods that are more effective in oral mucosal disease education are therefore required.

Problem-based learning (PBL) is a new teaching method that involves discussing problems. Popular in North America since 1969, it has been applied to medical teaching in major medical colleges and universities worldwide and has been recognized by the World Federation for Medical Education and the World Health Organization (1-3). The PBL teaching method treats students as the subjects (4) and focuses on problems with the aim of stimulating their interest in learning and improving their self-learning, problem-analyzing, and problem-solving skills. Through addressing, analyzing, and solving problems, as well as group discussion, PBL also aims to help students develop a deeper understanding of the subject and to capture information more effectively. In PBL, students collect data themselves to solve problems, summarize them, and report their results. Donner et al. (2) believe that, contrary to past teaching methods where teachers served as the subject, in PBL, where students as regarded as the subjects, the teacher serves primarily as a guide, facilitator, or someone to answer questions. Also in contrast with the traditional model, in which knowledge is primarily conveyed by the teacher, students collect information themselves in PBL, primarily using the internet, libraries, and other means. This is a vital aspect of the PBL teaching method. Finucane et al. (1) opine that PBL allows students to learn independent problem-solving, as well as obtain fundamental, and even clinical, knowledge. Studies $(1,5)$ have shown that students can actively participate in the education process and acquire lifelong learning ability through PBL. Fincham et al. (6) found that students taught by the PBL method achieved better results in the US National Board Dental Examinations (Part I).

Case-based learning (CBL), also known as caseoriented learning, is a teaching method that involves case discussion (7). Clinical cases are the subject in this method of teaching, and students are allowed contact with "clinical patients" in a limited teaching space. In this environment, theory is organically combined with clinical practice and is given a better sense of reality $(8,9)$. Garvey et al. (10) believe that the CBL pedagogical approach requires students to use their existing knowledge and clinical experience to solve clinical problems. Zhang et al. (11) are of the opinion that CBL helps students develop teamwork skills, reconcile their acquired knowledge, and develop a deeper understanding of the subject of study. CBL can stimulate the desire to learn in students and help them develop independent thinking and analysis skills, learn to integrate fragmented knowledge, and apply these skills in practice.

In recent years, many studies have explored the effectiveness of PBL and CBL. However, only a limited number of these studies have compared these two novel teaching methods, and studies that investigated the importance of teachers in these methods were even rarer. We therefore applied the PBL and CBL teaching methods to oral mucosal disease education in our hospital and compared their effectiveness. This study also focused on the role of teachers in these methods. Both teaching methods were introduced by the Teaching and Research Section of Oral Mucosal Disease of the School of Medicine at Shanghai Jiao Tong University.

We present the following article in accordance with the MDAR reporting checklist (available at http://dx.doi. org/10.21037/atm-21-165). 


\section{Methods}

Twenty-eight students enrolled in a seven-year program at the College of Stomatology at Shanghai Jiao Tong University were randomly selected and divided into four groups. Ten teachers from the Teaching and Research Section of Oral Mucosal Disease of the School of Medicine at Shanghai Jiao Tong University were responsible for teaching and assessing the students. The study was conducted in accordance with the Declaration of Helsinki (as revised in 2013). We did not apply for an "Ethical Statement". In this study, teachers and students were randomly selected. We sent questionnaires to each of them, and they filled them out anonymously. There is no sensitive and identifiable personal information factor involved. We believe that random questionnaires and survey results will not adversely affect the investigators. We believe that all participants have no ethical impact.

PBL was used with self-directed learning to teach the theory of oral mucosal diseases in the students' fourth academic year, while CBL was applied by presenting specific cases in the students' internships. Twenty classes were observed, ten each of PBL and CBL. Each teacher taught one class using PBL and one class using CBL. Preparations were made prior to classes through group discussion. During each PBL and CBL class, each group's spokesperson gave presentations; students took turns to act as spokesperson.

In classes taught by the PBL method, teachers asked questions about a specific case related to knowledge conveyed in that class. This was followed by group and inter-group discussions. Students were given two weeks to collect information, after which the spokesperson summarized and reported the results to the class. A summary and evaluation were then provided by teachers. The problems introduced by teachers were closely related to course content and were focused on vertical and horizontal connections and the combination of theory with clinical practice. In their final summaries, teachers focused on knowledge integration, highlighting key points, points of difficulty, points of doubt, and new points. They also ensured the teaching content was concise, broad, and novel to develop the students' independence and creativity.

In classes taught by the CBL method, all cases for discussion involved clinically diagnosed patients that would undergo treatment in the near future. Teachers prepared relevant medical information in advance (such as past medical history, clinical manifestations, and auxiliary and
$\mathrm{X}$-ray examination results), as well as the precise diagnosis and specific treatment plan. Teachers described the cases and the problems required to be solved. The students then conducted group discussions and were given two weeks to collect data. In the following class, the spokesperson reported the diagnosis and the treatment plan developed in group discussions. Inter-group discussions were carried out to address any differences in opinion between the two discussion groups. Finally, teachers summarized the results, provided students with the precise diagnosis and treatment plans, and evaluated the performance of the two groups. The evaluation was primarily based on five aspects: the ability to analyze the clinical manifestations of the given case; the ability to analyze auxiliary examination results; accuracy of diagnosis; accuracy and comprehensiveness of treatment plans; and diagnostic ability. To allow for adequate classroom discussion, each class lasted for three hours.

After 20 classes, teachers assessed the effect of PBL by the students' class performance, data collection ability, and group cooperation. The effect of CBL was assessed by the students' history-taking, diagnosis and antidiastole and case analysis ability. Data was collected by questionnaire survey. The questionnaire consisted of three parts. The first two parts focused on the teaching efficiency of the two methods and included seven questions. The third part was a comparison of PBL and CBL and included six questions.

\section{Statistical analysis}

All survey data were statistically analyzed by rank-sum test using SPSS Statistics 20.

\section{Results}

A total of 28 students and 10 teachers were analyzed. Of these 38 participants, the average scores for the first four questions in part $1(\mathrm{CBL})$ and part $2(\mathrm{PBL})$ of the questionnaire were more than 3 (Table 1). This indicated both teachers and students found CBL and PBL to be effective. The average score for the fifth question with regards to both $\mathrm{CBL}$ and $\mathrm{PBL}$ was less than 2. This indicated that neither teachers nor students thought either teaching method took too much time and become inconvenient. For the sixth question, the average score from both students and teachers with regards to CBL was more than 3 , but the average score for teachers with regards to 


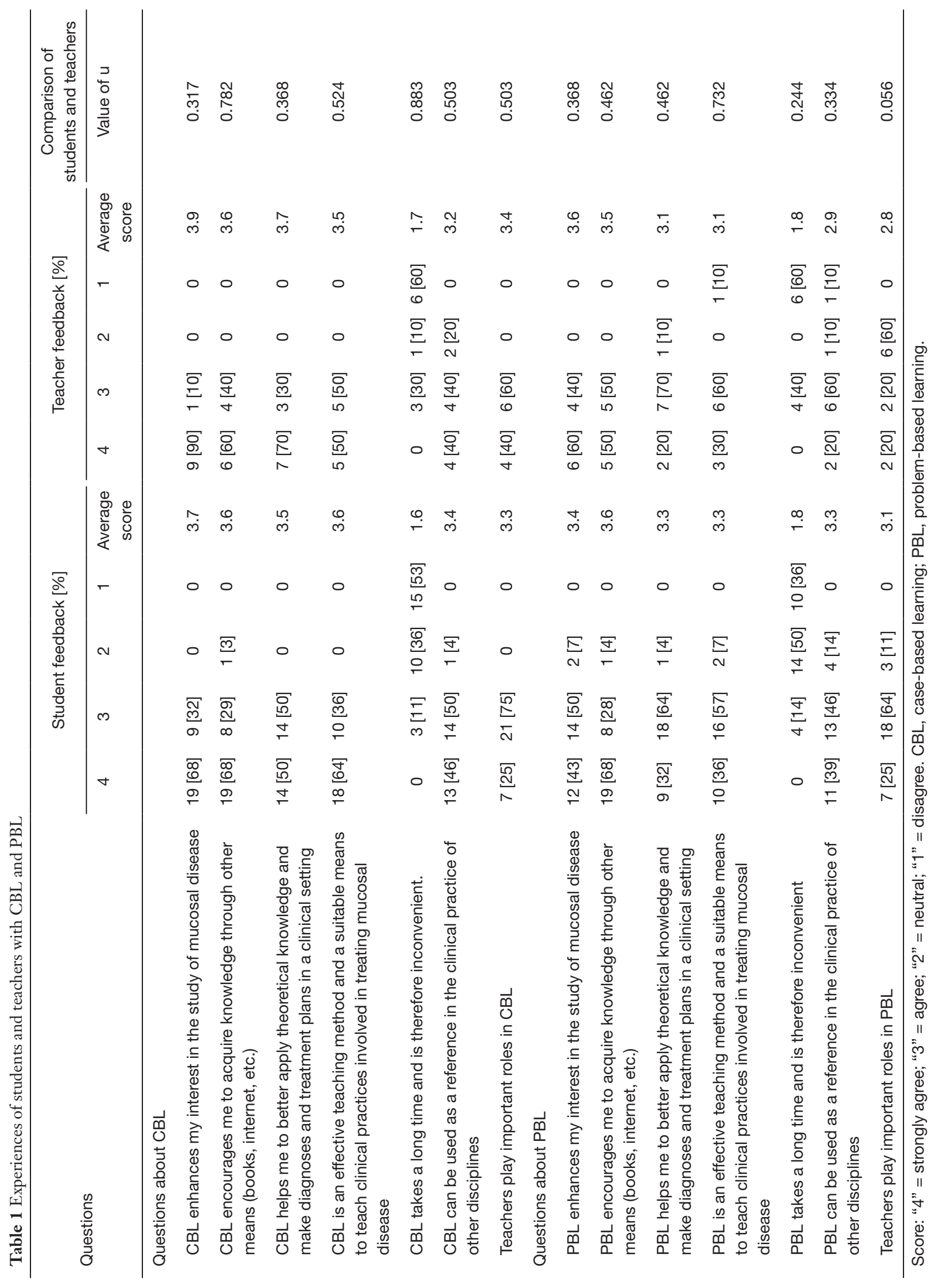


Table 2 Comparison of student and teacher views on CBL and PBL

\begin{tabular}{|c|c|c|c|c|c|}
\hline \multirow{2}{*}{ Questions } & \multicolumn{2}{|c|}{ CBL } & \multicolumn{2}{|c|}{ PBL } & \multirow{2}{*}{$\begin{array}{c}\begin{array}{c}\text { Comparison of students } \\
\text { and teachers }\end{array} \\
\text { Value of } u\end{array}$} \\
\hline & Students [\%] & Teachers [\%] & Students [\%] & Teachers [\%] & \\
\hline $\begin{array}{l}\text { Which better encourages acquiring knowledge } \\
\text { through other means (books, internet, etc.)? }\end{array}$ & $18[64]$ & $4[40]$ & $10[36]$ & $6[60]$ & 0.272 \\
\hline Which takes more time? & $2[7]$ & $2[20]$ & 26 [93] & $8[80]$ & 0.568 \\
\hline $\begin{array}{l}\text { Which better promotes teacher-student } \\
\text { interactions? }\end{array}$ & 18 [64] & $7[70]$ & $10[36]$ & $3[30]$ & 0.807 \\
\hline
\end{tabular}

CBL, case-based learning; PBL, problem-based learning.

PBL was 2.9. This apparently low score may be due to the fact that PBL was a new teaching model with which they were unfamiliar and they were unsure whether this method could be used as a reference in the clinical practice of other disciplines. There was no difference found between teacher and student feedback ( $\mathrm{u}>0.05)$.

The average scores for the seventh question indicated that neither teachers nor students thought teachers were unimportant in either PBL or CBL. More than half of the students thought that teachers played an important role in both CBL and PBL, and more than half of the teachers thought that teachers were important in CBL and were of average importance in PBL.

As shown in Table 2, students thought that CBL better enhanced their study of oral mucosal disease and encouraged them to be more active in acquiring knowledge of the disease through other means (books, internet, etc.). They also thought that CBL helped them better apply theoretical knowledge in clinical practice, improved their ability to make diagnoses and treat patients with oral mucosal disease, and promoted teacher-student interaction. PBL was considered more time consuming and promoted better student-student interaction. In contrast to students, teachers thought that PBL encouraged students to be more active in acquiring oral mucosal disease knowledge through other means (books, internet, etc.).

The questionnaire recovery rate was $100 \%$. There were no significant differences in CBL and PBL scores between teachers and students $(\mathrm{u}<0.05)$.

\section{Discussion}

Our results showed that both PBL and CBL enhance teaching quality and efficiency. PBL mostly improved students' knowledge acquisition, while CBL focused on the use of that knowledge.

In this study, all participants had completed their high school education. The traditional teaching method, in which teachers talk and students listen, is widely applied in secondary education in China. Therefore, the use of CBL and PBL teaching methods for the same group of students allowed them to experience the differences between these new teaching methods and traditional teaching methods, as well as the differences between CBL and PBL. The teachers who participated in the program, in teaching with these new methods for the first time, experienced the transition of the teacher's role and observed how students responded differently to these methods of teaching. The questionnaire indicates that both teachers and students generally accepted CBL and PBL teaching methods.

CBL and PBL are recognized worldwide and these methods have been studied by many domestic and international researchers. Allchin et al. (12) found that both CBL and PBL focus on a particular case or problem based on target knowledge. Despite their different bases, both methods introduce knowledge in a particular environment 
so that it has greater practical significance and the students' interest in learning is enhanced. Both methods also work to develop students' independent thinking and problemsolving ability. In both case-based and PBL, students were able to find solutions to given cases or solve given problems by critical and innovative thinking, active exploration, independent analysis, and mutual discussion, deepening their knowledge in the process $(13,14)$. Teachers primarily played a guiding role in this process. Major et al. (5) thought that, compared with the traditional "spoon-feeding" teaching method, PBL and CBL allow students to engage in active learning, exert their subjective initiative, and achieve better learning outcomes; this is consistent with our results. Many authors showed that students who have experienced PBL or CBL continue to actively participate in problem-solving and could solve new problems more effectively in the future, which is beneficial for the long-term development of students $(15,16)$.

Many more researchers, however, believe that CBL and PBL are fundamentally different. Williams et al. (17) are of the opinion that CBL is more effective for students with a corresponding knowledge base, while PBL encourages students to participate in the exploration of clinical cases and acquire fundamental knowledge. These authors also opine that PBL is primarily student-centered, while CBL requires greater teacher participation. Richards et al. (18) believes that knowledge gained from PBL is relatively limited, whereas CBL helps students gain broader knowledge. Teachers can explain a specific disease or treatment method for a specific clinical case during CBL. Zhang et al. (11) opine that PBL can stimulate students' interest in learning and help them develop teamwork and critical thinking skills; they think it is more suitable for the early gain of theoretical knowledge. The CBL teaching method is often combined with actual cases to inspire students to think, solve problems, and develop their own reasoning ability. CBL is therefore more suitable for students who have completed studies in fundamental oral medicine. The primary difference between PBL and CBL is that $\mathrm{CBL}$ require students to find solutions to cases, while PBL uses cases to encourage students to acquire knowledge in related fields.

Due to this, many educators believe that the role of teachers in CBL or PBL courses is limited to introducing the case. Conversely, although students solve problems in PBL and make diagnoses and treatment plans in CBL without assistance, teachers are required to provide appropriate direction and guidance. In this study, most participants believed that teachers were important in both PBL and CBL. Students thought that, without teachers, the courses might take more time and be less effective.

As shown in this study, PBL can develop students' learning autonomy, emphasize self-guidance in the learning process, and stimulate the desire for knowledge. On the other hand, CBL is focused on the application of knowledge to clinical cases, encouraging students to reconcile their existing knowledge and apply it, and to develop appropriate clinical thinking and language skills, laying a solid foundation for their future role as clinicians (19). The Teaching and Research Section of Oral Mucosal Disease at our college will therefore continue to implement PBL and CBL, collect further feedback from students, and perform long-term follow-up surveys to continually innovate and improve the quality of teaching with regard to oral mucosal disease.

This study was based on the current teaching system of stomatology in Shanghai Jiao Tong University. Before entering clinics, students received PBL and CBL. This kind of teaching method helps to increase their understanding about the features of oral mucosal disease. In summary, both teachers and students find PBL and CBL to be effective teaching methods. Despite their differences, neither is better or worse than the other, and their combination might enhance teaching effectiveness. In addition, although new teaching methods encourage students to learn autonomously, guidance from teachers is indispensable. Therefore, during the transition from traditional teaching methods to PBL and CBL, teachers should adapt their teaching methods and students should adjust their attitudes toward learning and make use of extensive learning resources, such as multimedia libraries and library reading rooms. Teaching methods will not improve overnight: it requires both teachers and students to fully participate and provide feedback so that positive adjustments can continually be made (20).

\section{Acknowledgments}

We acknowledge this work was supported by the Motivation plan for clinical teaching of Shanghai Ninth People's Hospital, Shanghai Jiao Tong University School of Medicine (No. 2017).

Funding: This study was supported by the Motivation plan for clinical teaching of Shanghai Ninth People's Hospital, Shanghai Jiao Tong University School of Medicine (No. 2017). 


\section{Footnote}

Reporting Checklist: The authors have completed the MDAR reporting checklist. Available at http://dx.doi.org/10.21037/ atm-21-165

Data Sharing Statement: Available at http://dx.doi. org/10.21037/atm-21-165

Conflicts of Interest: All authors have completed the ICMJE uniform disclosure form (available at http://dx.doi. org/10.21037/atm-21-165). The authors have no conflicts of interest to declare.

Ethical Statement: The authors are accountable for all aspects of the work in ensuring that questions related to the accuracy or integrity of any part of the work are appropriately investigated and resolved. The study was conducted in accordance with the Declaration of Helsinki (as revised in 2013). We did not apply for an "Ethical Statement". In this study, teachers and students were randomly selected. We sent questionnaires to each of them, and they filled them out anonymously. There is no sensitive and identifiable personal information factor involved. We believe that random questionnaires and survey results will not adversely affect the investigators. We believe that all participants have no ethical impact.

Open Access Statement: This is an Open Access article distributed in accordance with the Creative Commons Attribution-NonCommercial-NoDerivs 4.0 International License (CC BY-NC-ND 4.0), which permits the noncommercial replication and distribution of the article with the strict proviso that no changes or edits are made and the original work is properly cited (including links to both the formal publication through the relevant DOI and the license). See: https://creativecommons.org/licenses/by-nc-nd/4.0/.

\section{References}

1. Finucane PM, Johnson SM, Prideaux DJ. Problembased learning: its rationale and efficacy. Med J Aust 1998;168:445-8.

2. Donner RS, Bickley H. Problem-based learning in American medical education: an overview. Bull Med Libr Assoc 1993;81:294-8.

3. Wang G, Tai B, Huang C, et al. Establishing a multidisciplinary PBL curriculum in the School of
Stomatology at Wuhan University. J Dent Educ 2008;72:610-5.

4. Bian Z, Fan MW, Tai BJ. Application of Problem-based learning in Dental Education. Journal of Oral Science 2006;22:448-50.

5. Major $\mathrm{CH}$, Palmer B. Assessing the effectiveness of problem-based learning in higher education: Lessons from the literature. Academic Exchange Quarterly 2001;5:4-9.

6. Fincham AG, Shuler CF. The changing face of dental education: the impact of PBL. J Dent Educ 2001;65:406-21.

7. Kim S, Phillips WR, Pinsky L, et al. A conceptual framework for developing teaching cases: a review and synthesis of the literature across disciplines. Med Educ 2006;40:867-76.

8. Miflin BM, Campbell CB, Price DA. A conceptual framework to guide the development of self-directed, lifelong learning in problem-based medical curricula. Med Educ 2000;34:299-306.

9. Du GF, Li CZ, Shang SH, et al. Practising case-based learning in oral medicine for dental students in China. Eur J Dent Educ 2013;17:225-8.

10. Garvey MT, O'Sullivan M, Blake M. Multidisciplinary case-based learning for undergraduate students. Eur J Dent Educ 2000;4:165-8.

11. Zhang SY, Zheng JW, Yang C, et al. Case-based learning in clinical courses in a Chinese college of stomatology. J Dent Educ 2012;76:1389-92.

12. Allchin D. Problem- and case-based learning in science: an introduction to distinctions, values, and outcomes. CBE Life Sci Educ 2013;12:364-72.

13. Singhal A. Case-based Learning in Microbiology: Observations from a North West Indian Medical College. Int J Appl Basic Med Res 2017;7:S47-S51.

14. Bassir SH, Sadr-Eshkevari P, Amirikhorheh S, et al. Problem-based learning in dental education: a systematic review of the literature. J Dent Educ 2014;78:98-109.

15. Rezaee R, Mosalanejad L. The effects of case-based team learning on students' learning, self regulation and self direction. Glob J Health Sci 2015;7:295-306.

16. Kong LN, Qin B, Zhou YQ, et al. The effectiveness of problem-based learning on development of nursing students' critical thinking: a systematic review and metaanalysis. Int J Nurs Stud 2014;51:458-69.

17. Williams B. Case based learning--a review of the literature: is there scope for this educational paradigm in prehospital education? Emerg Med J 2005;22:577-81. 
18. Richards PS, Inglehart MR. An interdisciplinary approach to case-based teaching: does it create patientcentered and culturally sensitive providers? J Dent Educ 2006;70:284-91.

19. Kumar V, Gadbury-Amyot CC. A case-based and teambased learning model in oral and maxillofacial radiology. $\mathrm{J}$
Dent Educ 2012;76:330-7.

20. Nadershahi NA, Bender DJ, Beck L, et al. An overview of case-based and problem-based learning methodologies for dental education. J Dent Educ 2013;77:1300-5.

(English Language Editor: B. Madden)

Cite this article as: Wang H, Xuan J, Liu L, Shen X, Xiong Y. Problem-based learning and case-based learning in dental education. Ann Transl Med 2021;9(14):1137. doi: 10.21037/atm21-165 